\author{
Samson Zegeye ${ }^{1}$ and Endalew Gemechu \\ Sendo ${ }^{2 *}$ \\ ${ }^{1}$ Alkan Health Science Business and Technology \\ College, Addis Ababa, Ethiopia \\ ${ }^{2}$ Addis Ababa University, College of Health Science, \\ School of Nursing and Midwifery, Addis Ababa, \\ Ethiopia, P.O. Box 1176, Ethiopia \\ Dates: Received: 16 November, 2014; Accepted: \\ 08 January, 2015; Published: 10 January, 2015 \\ *Corresponding author: Endalew Gemechu \\ Sendo, Addis Ababa University, College of Health \\ Science, School of Nursing and Midwifery, Addis \\ Research Article

\section{Adherence to Antiretroviral Therapy among Hiv-Infected Children Attending Hiwot Fana and Dil-Chora Art Clinic at Referral Hospitals in Eastern Ethiopia} Ababa, Ethiopia, P.O. Box 1176, Ethiopia, E-mail: endalewaau2012@gmail.com

www.peertechz.com

Keywords: ART Adherence rate; Pediatrics HIVI AIDs; Ethiopia

Abstract

Background: The success of antiretroviral therapy (ART) depends on a high level of adherence to a life-long regimen of antiretroviral drugs (ARVs). Adherence is a concern in children because of factors relating to children such as age, disclosure status of HIV sero- status, and understanding of the medication. Few studies have determined the level of adherence of ART among children since the scale-up of access to ARVs in the study areas. This study was thus undertaken to determine the level of ART adherence among pediatric pat ients at an ART clinic, the reasons for non-adherence, and the factors associated with adherence, according to mothers/caregivers' reports.

Methods: Hospital based cross-sectional descriptive study design combining quantitative and qualitative methods was used. Three hundred thirteen HIV-positive children attending the ART center of referral hospitals were recruited in this study. The study was conducted from January - February 2013. An interviewer administered questionnaire was used to collect data. Data were entered in the Epi info software version 3.5.1 and then exported to the SPSS version 16 for quantitative analysis.

Results: Adherence to ART in 313 HIV positive children during the past three and seven days was assessed, and $310(99 \%)$ and $304(97 \%)$ of them took greater than $95 \%$ of the total prescribed doses, respectively. According to the care givers' report, the average rate of adherence to ART among children was $284(90.7 \%)$ in the one month recall period prior to the study. Disclosure of the child's sero status to the child, age of the child, occupational status, caregiver's relationship with child, and caregiver's knowledge of ARV treatment were factors independently associated with adherence to ART.

Conclusion: The current study showed that the level of adherence to antiretroviral therapy was found to be high. Health care providers should reinforce adherence counseling during follow up and address proper usage of medication reminders. Further study on adherence rate and its determinants with multiple adherence measurements to determine the barriers to adherence is also recommended.

\section{Introduction}

HIV/AIDS is one of the public health challenges in the world. In 2009, it was estimated that over 33.3 million people were living with HIV/AIDS worldwide, with 2.5 million of these being children under 15 years of age. The epidemic is worse in developing countries, particularly in Sub-Saharan Africa, with 22.5 million people living with HIV/AIDS by the end of 2009 [1]. Mother to Child Transmission (MTCT) is the largest source of infection in children below the age of 15 years. Without treatment, $15-30 \%$ of babies born to HIV positive women become infected with HIV during pregnancy and delivery. Furthermore, an additional $5-20 \%$ becomes infected through breastfeeding [2].

Adherence is defined as "the extent to which a person's behavior - taking medication, following a diet, and/or executing lifestyle changes, corresponds with agreed recommendations from a health care provider". Adherence is a major factor in determining the degree of viral suppression achieved in response to antiretroviral therapy
[3]. The goals of ARV therapy for children are to increase survival, improve quality of life and decrease HIV-related morbidity and mortality [4].

For ART to work effectively, adherence is very crucial. The recommended optimal adherence level for ART to be effective is above 95 percent [5]. Any patient who misses more than 3 dosages in a one month treatment course is considered to have achieved suboptimal adherence which is less than $95 \%$ [6]. A level of adherence which is greater than $95 \%$ (optimal adherence) suppresses viral replication and prevents the development of resistance and treatment failure. Thus, there is evidence that failure to adhere to the prescribed treatment regimen is associated with adverse clinical outcomes. Then, efforts to improve adherence rates are likely to result in improved health outcomes.

Adherence to ART is influenced by multiple factors and identification of these factors is necessary to get complete adherence to ART as depicted in conceptual framework beneath (Figure 1). 


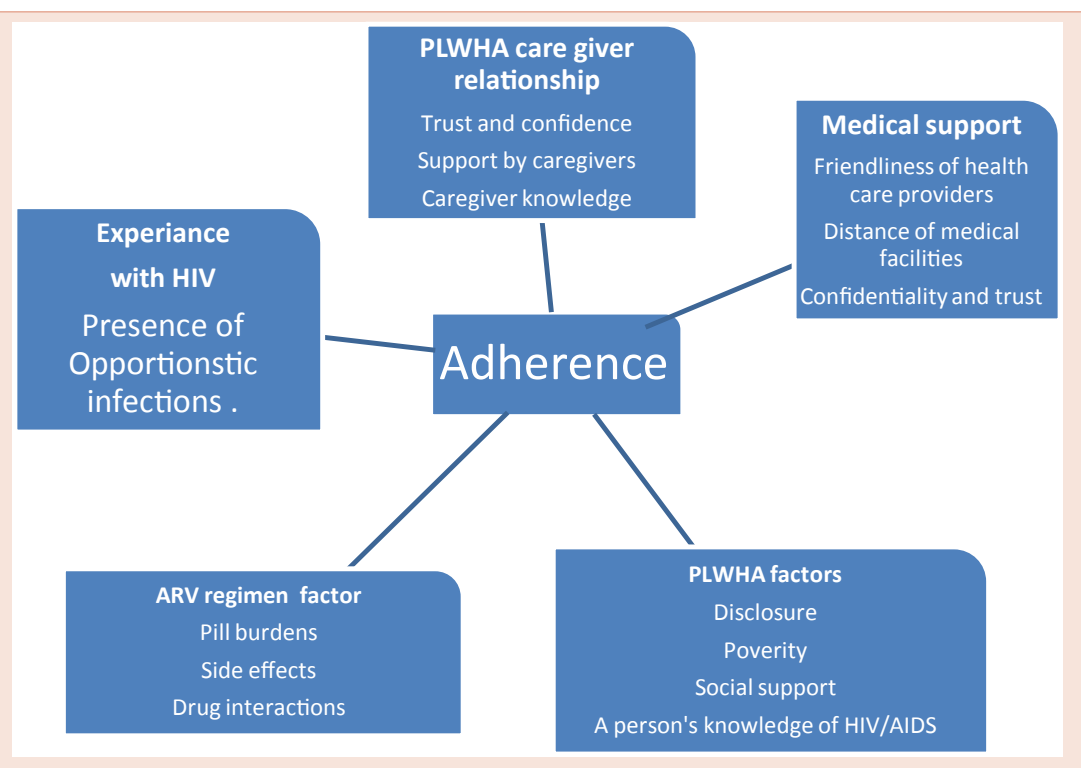

Figure 1: Conceptual Framework for the Assessment of Adherence to Antiretroviral Therapy among Children Living with HIV (Adopted from SAfAIDS, WHO and modified) [33].

In contrast to the above -mentioned literatures, suboptimal adherence rates had been reported in Africa; $88 \%$ in South Africa [7,8], and $80 \%$ in Atlanta [9]. Similar trend is observed in Ethiopia: $83 \%$ at two hospitals in Oromiya [10], 88.3\% in Yirgalem Hospital [11], and $81.2 \%$ in three hospitals in Addis Ababa [12].

In Ethiopia, there are 800,000 people living with HIV/AIDS and $1.5 \%$ of population aged $15-49$ is infected with HIV [13]. In Ethiopia, several policies and guidelines are in place to support the implementation and scale-up of the national response, including the National HIV/AIDS Policy, the National Strategic Framework on the Prevention and Control of HIV/AIDS, the Supply and use of ARV Drugs policy. Based on these documents, and on the recommendations of the United Nations General Assembly Special Session on HIV/AIDS (UNGASS), the Government of Ethiopia launched its fee-based ART initiative in 2003 and free ART initiative in 2005 [14]. After 2005, HIV care and ART services were further decentralized in Ethiopia. Private hospitals and health centers started delivering ART and HIV care in June 2006[15].

To strengthen adherence to ART in HIV-infected children, it is indispensable to identify factors that affect adherence and to look at the possible interventions to improve adherence. In view of this, it was imperative that a study be conducted to assess levels of adherence among children on ART and factors associated with adherence at ART clinics in the study settings. We anticipated that the data would inform the management of hospitals, $\mathrm{MOH}$ and other policy makers in Ethiopia on measures to limit non-adherence, and improve and/or maintain adherence to ART in HIV infected children.

\section{Materials and Methods}

\section{Study area and period}

The study was conducted from January - February 2013 in Harar and Dire Dawa referral hospitals at Hiwot Fana and Dil-Chora pediatric ART Clinic. Harar is one of the ancient cities in Ethiopia that is located at $525 \mathrm{Km}$ east of the capital city of Addis Ababa. According to the FMOH, health, and health related indicator reports of Ethiopia for 2011, the total population of Harar is about 203,168. HIV prevalence in Harar region and Dire Dawa town is $1.1 \%$ and $1.2 \%$, respectively. Currently, there are seven ART clinics in the study settings. Among these seven ART clinics, two Hospital-based ART clinics were purposefully selected based on their client flow during the study period. The hospitals started providing free ART services to HIV infected people in accordance with the national ART guidelines in 2005. Currently, the ART clinics provide HIV related services for both adults and children.

\section{Study design}

Hospital based cross-sectional descriptive study design combining quantitative and qualitative methods was used.

\section{Selection criteria}

Selection criteria for health facilities included public health facilities that had ART Clinic and provided HAART to more than 100 children for at least 12 months by December 2012. Two referral hospitals met these criteria: Hiwot Fana and Dil-Chora ART clinics, which were purposely selected. Inclusion criteria for participants were: all HIV- positive children under 15 years who were treated with HAART for at least 12 months prior to the commencement of the study. At the time of the study, the pediatric ART clinics of the selected hospitals had 395 patients in the age range of 3 to 14 years registered for ART. A total of 313(127 from Hiwot Fana and 186 from Dil-Chora) caregivers of children receiving antiretroviral therapy for the last 2 months prior to the study in the selected hospitals met the criteria and children in the age group of 3 months to 14 years were included in the study. Thirty two parents/caregivers were not willing 
to take part in the study while 50 of them didn't meet the inclusion criteria (they started ART 2 weeks prior to the study)

\section{Measurement}

This study measured HIV-infected children's adherence to HAART through caregivers' report of missed doses. Adherence to anti-retroviral regimen was recorded in this study using patients' self report. They were interviewed on the number of pills missed in the past three days, past seven days and past month. The caregivers were asked if they had missed doses during the prescribed dosing intervals. In this study, good adherence was defined as having taken at least $95 \%$ of the totally prescribed pills at the prescribed dosing intervals. Patients/caregivers who reported an intake of more than $95 \%$ of the prescribed medications were considered to be adherent. If the child failed to achieve $\geq 95 \%$ adherence to ART regimen in the prescribed schedules, the adherence was then considered poor adherence.

\section{Data collection tools and procedures}

Quantitative and qualitative data was collected by the lead investigators and trained research assistants. Data was collected by using a pretested and structured questionnaire administered by face to face interviews with caregivers by four trained female nurses working in the ART Clinic. The questionnaire was adapted from other similar studies [8-11]. The questionnaire was originally developed in English; then translated into local language (Oromifa) and back into English to ensure its accurateness by an expert. To ensure quality of the data, the questionnaire was pretested in $5 \%$ of the sample size in similar set up before the actual data collection. The questionnaire consists of three parts which include: socio-demographic characteristics (age, gender, ethnicity, religion, educational status and occupational status of the caregiver, knowledge of caregiver about ART, relationship with the child, age of the child, gender of the child, family size); health care provider/program related factors to adherence; and reasons of missing doses.

This study was also triangulated with qualitative method. For the qualitative part, an in-depth interview was used for five primary care givers of the children who were purposively selected. All participants were interviewed in a private room in their local language.

\section{Statistical Analysis}

Our study involved quantitative and qualitative analysis. Data were entered in the Epi info software version 3.5.1 and then exported to the SPSS version 16 for the quantitative analysis. Mean and standard deviations were calculated for continuous variables whereas percentages were calculated for categorical variables. All continuous variables were categorized and analyzed using the Chi square test and $\mathrm{P}$ value $<0.05$ was considered significant. The association was measured by Odds ratio (OR). Predictors of non- adherence were identified using bivariate and multivariate logistic regression analysis. Factors with P-value 0.2 or less at bivariate analysis were selected for further multivariate analysis and entered into a logistic regression model.

Qualitative analyses were done using manifest content analysis. Data were transcribed, read thoroughly line by line and a coding framework initiated using an excel spread sheet. Data were analyzed for content guided by the objectives of the study. Corresponding data were summarized with supporting quotes and presented in verbatim.

\section{Ethical approval}

The ethical approval for this study was obtained from Haramaya University, College of Health Sciences, Institutional Research Ethics Review Committee. Permission was also obtained from Harar regional and Dira Dawa city Administration Health Bureaus and the respective hospitals' ART clinic. Prior to enrollment for the study, care givers were properly counseled in their own language and verbal informed consent was taken from them. ART follow-up records were retrieved by the nurses working in the ART units, and personal information of the participants was kept confidential. Mothers/ care givers who consented to participate were thereafter interviewed.

\section{Results}

\section{Socio-demographic characteristics}

A total of 313(127 from Hiwot Fana and 186 from Dil-Chora) caregivers of children were included in the study. The mean (SD) and the median age of the primary care givers were $36( \pm 10.43)$ and 35 , respectively. A majority $258(82.4 \%)$ of the study participants were Christian by religion and 131 (41.9\%) were married. Regarding the educational status of the care givers, the most 133 (42.5\%) attended primary education while $70(22.4 \%)$ had no formal education. Two hundred and fifty three $(80.8 \%)$ of care givers had a family size of less than five. One hundred and eighty eight (60.1\%) of the caregivers were biological parents of the children.

Among 313 children, more than half 166 (53.0\%) were female. The mean age of the children was 7.8 (SD, 3.5) years. The age of children ranged from 3-14 years and 138 (44.1\%) were older than 9 years followed by 119 (38.0\%) between 6-8 years and $56(17.9 \%)$ between age 3-5 years. Regarding the educational status of children, $104(33.2 \%)$ of them were between 1-4 grade (primary school), 93 (29.4\%) of them were at kindergarten, 37 (11.8) of them were between 5-8 grade and 79 (25.2) children not yet started school (Table 1).

\section{Knowledge of caregivers towards ART}

Of the respondents, 280 (89.4\%), were aware of ART before their child started treatment. For the knowledge assessment questions, 306 (97.8\%) of the respondents knew the types of medication the child was taking and 304 (97.1\%) of them knew that children taking ART would be required to take the medications for the rest of their life to delay AIDS progression.

These findings were also supported by Qualitative analysis. The most common theme reported was that ARVs are drugs that restore immunity, for instance one client reported, "ARV is a drug that is taken to enhance immunity if a person who has HIV/AIDS has little immunity". (In-Depth Interview, care giver 22 year-old) Another common theme that was emerged was that ARVs are drugs that prolong client's life. On this theme one care giver reported as, "ARV is a drug that is given to people with HIV to prolong their lives" (InDepth interview, care giver 27 year-old).

\section{Level of ART adherence}

This study measured HIV-infected children's adherence to 
Table 1: Socio-demographic characteristics of the respondents, February 2013.

\begin{tabular}{|c|c|c|}
\hline Characteristics & Number $(\mathrm{N}=313)$ & Percent \\
\hline $\begin{array}{l}\text { Age of care giver }(Y r) \\
<20 \\
20-30 \\
31-39 \\
40-59 \\
\text { Mean } \\
\text { Median }\end{array}$ & $\begin{array}{c}9 \\
138 \\
117 \\
49 \\
36( \pm 10.43) \\
35\end{array}$ & $\begin{array}{c}2.9 \\
44.1 \\
37.4 \\
15.6\end{array}$ \\
\hline $\begin{array}{l}\text { Marital Status } \\
\text { Married } \\
\text { Single } \\
\text { Divorced /Separated }\end{array}$ & $\begin{array}{c}131 \\
60 \\
122\end{array}$ & $\begin{array}{c}41.8 \\
19.2 \\
39\end{array}$ \\
\hline $\begin{array}{l}\text { Family size } \\
\text { Less than five } \\
\text { More than five }\end{array}$ & $\begin{array}{c}253 \\
60\end{array}$ & $\begin{array}{l}80.8 \\
19.2\end{array}$ \\
\hline $\begin{array}{l}\text { Religion } \\
\text { Christian } \\
\text { Muslim }\end{array}$ & $\begin{array}{c}258 \\
55\end{array}$ & $\begin{array}{l}82.4 \\
17.6\end{array}$ \\
\hline $\begin{array}{l}\text { Employment status } \\
\text { Employed } \\
\text { Not employed }\end{array}$ & $\begin{array}{c}55 \\
258\end{array}$ & $\begin{array}{l}17.6 \\
82.4\end{array}$ \\
\hline $\begin{array}{l}\text { Educational status } \\
\text { No formal education } \\
\text { Elementary } \\
\text { Secondary } \\
\text { College/University }\end{array}$ & $\begin{array}{c}70 \\
133 \\
110 \\
0\end{array}$ & $\begin{array}{c}22.4 \\
42.5 \\
35.1 \\
0\end{array}$ \\
\hline $\begin{array}{l}\text { Relationship with child } \\
\text { Biological parent } \\
\text { Non- Biological parent }\end{array}$ & $\begin{array}{l}188 \\
125\end{array}$ & $\begin{array}{l}60.1 \\
39.9\end{array}$ \\
\hline $\begin{array}{l}\text { Age of the child (in } Y r \text { ) } \\
3-5 \\
6-8 \\
>9 \\
\text { Mean age }\end{array}$ & $\begin{array}{c}56 \\
119 \\
138 \\
7.8(\mathrm{SD}: \pm 3.5)\end{array}$ & $\begin{array}{l}17.9 \\
38.0 \\
44.1\end{array}$ \\
\hline $\begin{array}{l}\text { Sex of the child } \\
\text { Male } \\
\text { Female }\end{array}$ & $\begin{array}{l}147 \\
166\end{array}$ & $\begin{array}{l}47 \\
53\end{array}$ \\
\hline $\begin{array}{l}\text { Educational status } \\
\text { Kindergarten } \\
\text { Grade 1-4 } \\
\text { Grade 5-8 } \\
\text { Not started school }\end{array}$ & $\begin{array}{c}93 \\
104 \\
37 \\
79\end{array}$ & \\
\hline
\end{tabular}

HAART through caregivers' report of missed doses in the past three days, past seven days and past month. Adherence to ART in 313 HIV positive children during the past three and seven days was assessed and $310(99 \%)$ and $304(97.1 \%)$ of them took greater than 95\% of the total prescribed doses, respectively. According to the care givers' report, the average level of adherence to ART among children was $284(90.7 \%)$ in the one month recall period prior to the study. With regard to disclosure of HIV status, participants were asked whether they disclosed the child s HIV status. Among the caregivers, 236 (75.4\%) of them disclosed the child's sero- status to the child.

Most of respondents used some strategy to remind them to take their medication. The main devices used for adherence supports were mobile phone's alarms 194 (62\%) followed by an alarm clock 110 (35.1\%). Furthermore, $25.4 \%$ patients were reminded by relatives to take their medication, $1.5 \%$ had friends or peers remind them and the rest 9 (2.9) used no reminder to take their medication.
Qualitative analysis also showed that a reminder was the most common strategy that is used to take medication. The most common theme that was emerged from the respondents was the need for a reminder to take drugs, for example one respondent reported, "I always set mobile phone's alarm and remind my child to take her medication on time" (In-Depth Interview, care giver 37 year-old).

Despite the fact that other children need to be reminded to take their medication, some children on contrary remind their care giver to give them their medication as reported by one respondent, "My child usually reminds me to give him his medication timely" (InDepth Interview, care giver 35 year-old).

\section{Reasons for non-adherence}

Of the total children taking ART, 33 (10.5\%) of them had a history of missing at least one dose in the last month prior to the survey. The major reasons cited by the caregivers for missing doses were forgetfulness $14(42.4 \%)$, drug side effects $11(33.3 \%)$, run out of medications $5(15.1 \%)$ and care giver forgot it $3(9.1 \%)$.

Other commonly cited reasons by respondents in In-depth interview included not taking pills along with them, sleeping through dose. "When we travel for picnic we sometimes forget to take the pills along us and the child misses medication... She added, when my child sleeps early, I don't give him his pills, and when I realized it, I got very annoyed" (In-Depth Interview, care giver 28 year-old).

Patient- Health care provider relationship and health care system

Almost all of the caregivers, 310 (99\%), felt they have a good relationship with their health care providers and 300 (95.8\%) also have open communication. All the respondents had access to pharmacies whenever they wanted and were satisfied with the ease of scheduling appointments and confidentiality. Almost all of the respondents, 308 (98.4\%), were satisfied by the changes/improvement their child experienced from the treatment.

An informant said that: "In the beginning, the health care providers gave me information and advice me to initiate ART for my child. However, I was afraid to decide on the initiation of medication for my child but later when he was very sick I decided it. Now, praise to God, he is in a good health condition. I see lot of changes in my child since he has started medication" (In-Depth Interview, care giver 38 year-old).

\section{Factors associated with adherence to ART}

Through multivariate logistic regression; the age of the child $[\mathrm{AOR}=0.48[0.29-4.32]$, relationship with child $[\mathrm{AOR}=2.44,0.77$ 7.72], Occupational status $[\mathrm{AOR}=3.05,0.49-5.28]$, disclosure of the child's HIV status to the child [AOR $=5.02,0.37-8.03]$ and caregiver knowledge of ART medication $[\mathrm{AOR}=7.31,1.72-6.08]$ were independently associated with adherence to ART (Table 2).

\section{Discussion}

According to the care givers report, the level of adherence to ART among HIV positive children was $90.7 \%$ in one month recall period preceding to the study. The treatment adherence level found in this 
Table 2: Factors determining adherence among HIV+ children at Harar and Dire Dawa Hospitals ART Clinic, February 2013.

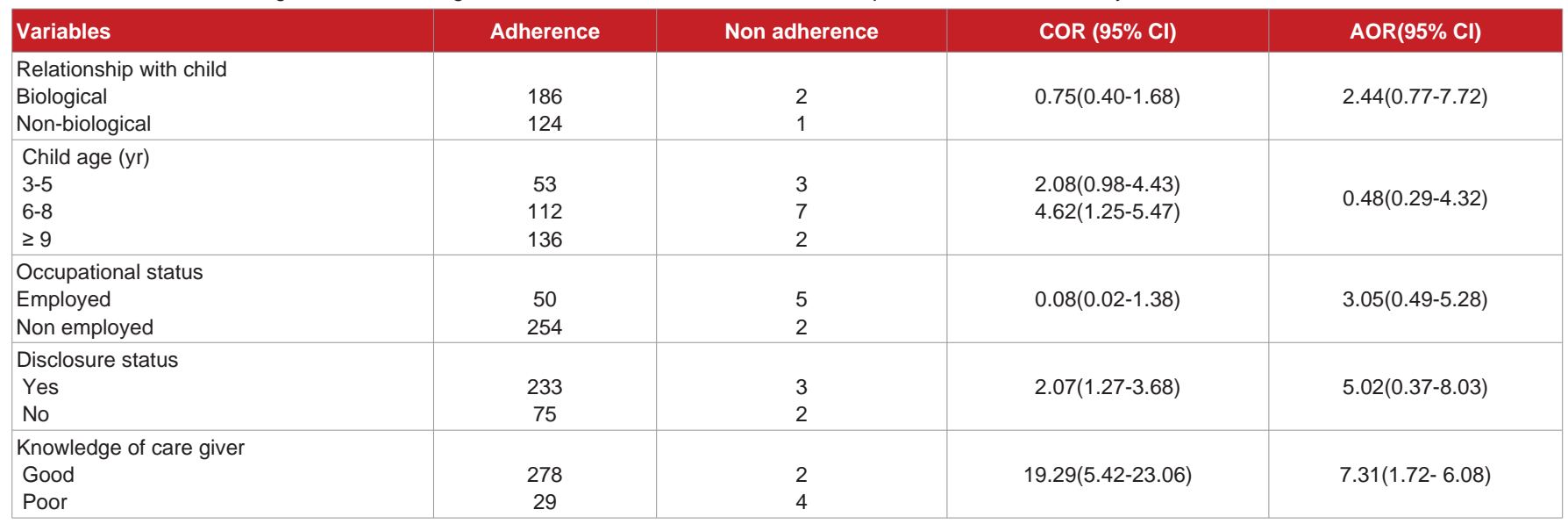

study was higher in comparison to studies conducted previously in Ethiopia at Oromiya Regional State (83\%)[10], Yirgalem Hospital (88.3\%) [11] and Addis Ababa (81.2\%) [15]. The difference might be due to mobilization activities that have been undertaken by government in the study setting to improve the ART service. This finding is, however, inconsistent with the study done in rural China by Wang and $\mathrm{Wu}$; where $81.8 \%$ of the patients reported $\geq 95 \%$ adherence on the previous 7 days of the study [16]. Nevertheless, the average adherence in this study is higher than study done in Nigeria; in which adherence is $85.5 \%$ [17] and study done at Taksin Hospital with reported adherence rate of $70 \%$ [18]. The probable reason for this difference may be difference in assessment methods. The present study used only self-report which might overestimate the measure of adherence. But multi- method adherence assessment including selfreport, the visual analogue scale, and the pill identification test and pill count was used in other studies. The other explanation might be that most of the children didn't experience any adverse effects of the medication since side effects are known to increase non adherence $[19,20]$.

In this sample of children living with HIV, 10.3\% did not fully adhere to their ART regimens.

Caregivers of non-adherent children reported that missed doses were most often due to forgetfulness (42.4\%), drug side effects (33.3\%), run out of medications (15.1\%) and care giver forgot it (9.1\%). Our finding in the current study is consistent with a study from Côte d'Ivoire on pediatric ART adherence, which found that missed doses were most commonly due to forgetfulness (40.5\%) [21]

In our present study, treatment adherence to ART was significantly associated with the age of the children. As the age of the child increased the level of adherence to treatment decreased, [AOR $=0.48,0.29-4.32]$, which is in agreement with a study from Gonder, Ethiopia [20].

However, our finding in this study is contradictory with other studies conducted in Nigeria, Togo, Italy and Brazil [22-25].

This decrease can be explained by care givers delegating treatment responsibilities to the child irrespective of the child's knowledge of the medications and their importance.
Disclosure is an essential step and has implications for adherence. Starting with disclosure as early as 8-9 years of age and combining it with specific support is central to increase children's adherence as they get older $[20,26]$. In our present study, the level of adherence was significantly high $[\mathrm{AOR}=5.0295 \% \mathrm{CI}$ : $0.37-8.03$ ] in children who were aware of their sero- status than in those who unaware of their status. This finding is in line with other studies $[25,26]$ but inconsistent with studies from Uganda and Democratic Republic of Congo [27]. These studies entail connection with professional and continuing counseling after illness disclosure to children.

Children commonly comply with their regimens if the caregiverchild relationship was strong, and did not if the caregiver-child relationships were awkward and lacked trust. These findings are particularly remarkable, given that $24.6 \%$ of children in our study had not been told their HIV status. Further investigation of how disclosure influences ART adherence is required in Ethiopian circumstance.

The study also revealed that caregivers of children with good knowledge about the disease were 7.3 times $[\mathrm{AOR}=95 \% \mathrm{CI}$ : 1.72 6.08] more likely to adhere to ART than their counterparts. This finding is similar to studies conducted in other regions of Ethiopia $[20,27,28]$.

The strengths of this study include a large number of patients were purposively sampled from Harar and Dire Dawa referral hospitals ART clinics in Eastern Ethiopia. This study was also triangulated with qualitative method.

However, there were several limitations to our study. Adherence data relied on reporting by caregiver, which is subject to recall and response bias. Using a technique, such as pill counting, to measure adherence may have yielded more accurate results. In the literature, self-reported adherence tended to produce estimates of adherence that were $10-20 \%$ higher than those from electronic drug monitoring [31,32]. To minimize these biases, we employed interviewers who were not allied with the selected ART clinics, and explained plainly to the patients the purpose of the study prior to interviewing them. In addition, we used a high cut-off for adherence level $(\geq 95 \%)$ and a 1 -month time period to measure the rate, which has proved effective to detect non-adherence [33]. 


\section{Conclusion}

The current study showed that the level of adherence to antiretroviral therapy was found to be high. Disclosure of the children's sero -status to the child, age of the child, occupational status, caregiver's relationship with child, and caregiver's knowledge of ARV treatment were factors independently associated with adherence to ART. Health care providers should reinforce adherence counseling during follow up and address proper usage of medication reminders. Further study on adherence rate and its determinants with multiple adherence measurements to determine the barriers to adherence is also recommended.

\section{Acknowledgment}

We are very grateful to Haramaya University, College of Health Sciences, and Institutional Research Ethical Review Committee. We would like to express our gratitude to the data collectors for their invaluable assistance during data collection. We are grateful to study subjects for their participation and willingness to be involved in the interview.

\section{Conflict of Interest and Funding}

The authors have not received any funding or benefits from industry or elsewhere to conduct this study. The authors declare that they have no competing interests.

\section{Authors' Contributions}

SZ carried out the study starting from conception, analysis and interpretation of data. EG participated in data analysis, interpretation and in critical review of the manuscript, and drafted the manuscript. Both authors have equal contributions. Both authors read and approved the final draft of the manuscript.

\section{References}

1. Joint United Nations Programme on HIVIAIDS (UNAIDS) and WHO (2011). A report on the global AIDS epidemic. 2009 [cited, April 13].

2. Chirag S (2007) Adherence to high activity antiretrovial therapy (HAART) in pediatric patients infected with HIV: Issues and Interventions. Indian J Pediatr 74: 55-60.

3. The working group on antiretroviral therapy and medical management of HIV infected children. (2001) Guidelines for the use of antiretroviral agents in pediatric HIV infection.

4. African Network for the care of children affected by AIDS -ANECCA. A Handbook on Pediatric AIDS in Africa; 2006.

5. Africa network for the care of children affected by AIDS. A hand book of pediatric AIDS in Africa. 2004.

6. Heyer A, Ogunbanjo GA (2006) Adherence to HIV anti-retroviral therapy part II: Which interventions are effective in improving adherence? SA Fam Pract 48: 6-10.

7. Nachega JB, Stein DM, Lehman DA, Hlatshwayo D, Mothopeng R, et al. (2004) Adherence to antiretroviral therapy in HIV-infected adults in Soweto, South Africa. AIDS Res Hum Retroviruses 20: 1053-1056.

8. Kebede Alemu (2014) Adherence to Highly Active Antiretroviral Therapy and Predictors of Non- Adherence among Pediatrics Attending Ambo Hospital ART Clinic, West Ethiopia. J HIV AIDS Infect Dis 2: 1-7.

9. Kalichman SC, Ramachandran B, Catz S (1999) Adherence to combination antiretroviral therapies in HIV patients of low health literacy. J Gen Intern Med 14: $267-273$
10. Awel M (2008) Antiretroviral adherence and its detriments among people living with HIVIAIDS on highly active antiretroviral therapy in two hospitals of ormoyia regional state," Ethiopia. Ethiopian Public Health Association (EPHA).

11. Marcos E, Worku A, Davey G (2008) Adherence to ART in PLWHA at Yirgalem hospital, South Ethiopia. The Ethiop J Health Dev 22: 174-179.

12. Parsons JT, Rosof E, Mustanski B (2007) Patient-related factors predicting HIV medication adherence among men and women with alcohol problems. J Health Psychol 12: 357-370.

13. Federal Ministry of health: National HIVIAIDS prevention and control office, AIDS in Ethiopia. Sixth report.

14. Therapy Programme in Ethiopia. Federal HIVIAIDS Prevention and Control Office 2007.

15. Abdulwadud O, Admassu K, Endale A, Tesfaye N, Teshome G, et al. (2011) Retrospective review of antiretroviral therapy program data in accredited private hospitals in Addis Ababa City Administration, Ethiopia. Ethiop J Health Dev 25: 110-115.

16. Wang X, Wu Z (2007) Factors associated with adherence to antiretroviral therapy among HIVIAIDS patients in rural China. AIDS 21: S149-155.

17. Uzochukwu BS, Onwujekwe OE, Onoka AC, Okoli C, Uguru NP, et al. (2009) Determinants of non-adherence to subsidized anti-retroviral treatment in southeast Nigeria. Health Policy Plan 24:189-196.

18. Wagner GJ (2004). Predictors of Antiretroviral Adherence as measured by self report, electronic monitoring, and medication diaries. AIDS patient care STD 16: 599-608.

19. Malta M, Maya L, Scott C, Fernando F, Francisco I (2005) Adherence to antiretroviral therapy:a qualitative study with physicians from Rio deJaneiro, Brazil, Cad Saúde Pública 21:1424-1432.

20. Dachew BA, Tesfahunegn TB, Birhanu AM (2014) Adherence to highly active antiretroviral therapy and associated factors among children at the University of Gondar Hospital and Gondar Poly Clinic, Northwest Ethiopia: a crosssectional institutional based study. BMC Public Health 14: 875.

21. Reddi A, Leeper SC (2008) Antiretroviral therapy adherence in children outcomes from Africa. AIDS 22: 906-907.

22. World Health Organization (2003) Scaling up Antiretroviral Therapy in Resource- Limited Settings treatment Guide Lines for Public Health. Geneva, Switzerland: World Health Organization.

23. Mukhtar M, Gwarzo D, Zubaida Farouk Ladan (2006) Preliminary investigation of adherence to antiretroviral therapy among children in Aminu Kano Teaching Hospital. Nigeria African J AIDS Res 5: 141-144.

24. Polisset J, Ametonou F, Arrive E, Aho A, Perez F (2009) Correlates of adherence to antiretroviral therapy in HIV-infected children in Lome, Togo, West Africa. AIDS Behav 13: 23-32.

25. Margaret A (2000) Factors affecting adherence to antiretroviral therapy. Clin Infect Dis 30: S171-S176.

26. Giacomet V, Aalbano F, Starace F, De Franciscis A, Giaquinto C, et al. (2003) Adherence to antiretroviral therapy and its determinants in children with human immunodeficiency virus infection: a multicentre, national study in Italy. Acta Paediatr 92: 1398-1402.

27. Mills EJ, Nachega JB, Buchan I, Orbinski J, Attaran A, et al. (2006) Adherence to antiretroviral therapy in sub-Saharan Africa and North America: a metaanalysis. JAMA 296: 679-690.

28. Azmeraw D, Wasie B (2012) Factors associated with adherence to highly active antiretroviral therapy among children in two referral hospitals, Northwest Ethiopia. Ethiop Med J 50: 115-124.

29. Biadgilign S, Deribew A, Amberbir A, Deribe K (2008) Adherence to highly active antiretroviral therapy and its correlates among HIV infected pediatric patients in Ethiopia. BMC Pediatr 8: 53. 
30. Arnsten JH, Demas PA, Farzadegan H, Grant RW, Gourevitch MN, et al (2001) Antiretroviral therapy adherence and viral suppression in HIV-infected drug users: comparison of self-report and electronic monitoring. Clin Infect Dis 33: 1417-1423.

31. Simoni JM, Kurth AE, Pearson CR, Pantalone DW, Merrill JO, et al. (2006) Self-report measures of antiretroviral therapy adherence: a review with recommendations for HIV research and clinical management. AIDS Behav 10: $227-245$
32. Kobin AB, Sheth NU (2011) Levels of adherence required for virologic suppression among newer antiretroviral medications. Ann Pharmacother 45 372-379.

33. South Africa AIDS (SAfAIDS) information and Dissemination service, 2006. HIV prevention and treatment care and support-A training package for community volunteers, Adherence Module 4: 2006.

Copyright: (c) 2015 Zegeye S, et al. This is an open-access article distributed under the terms of the Creative Commons Attribution License, which permits unrestricted use, distribution, and reproduction in any medium, provided the original author and source are credited. 